\title{
Effect of battery longevity on costs and health outcomes associated with cardiac implantable electronic devices: a Markov model-based Monte Carlo simulation
}

\author{
Jordana K. Schmier ${ }^{1}$ • Edmund C. Lau ${ }^{2}$. Jasmine D. Patel ${ }^{3}$ - Juergen A. Klenk ${ }^{1}$. \\ Arnold J. Greenspon ${ }^{4}$
}

Received: 5 May 2017 / Accepted: 6 October 2017 /Published online: 6 November 2017

(C) The Author(s) 2017. This article is an open access publication

\begin{abstract}
Introduction The effects of device and patient characteristics on health and economic outcomes in patients with cardiac implantable electronic devices (CIEDs) are unclear. Modeling can estimate costs and outcomes for patients with CIEDs under a variety of scenarios, varying battery longevity, comorbidities, and care settings. The objective of this analysis was to compare changes in patient outcomes and payer costs attributable to increases in battery life of implantable cardiac defibrillators (ICDs) and cardiac resynchronization therapy defibrillators (CRT-D).

Methods and results We developed a Monte Carlo Markov model simulation to follow patients through primary implant, postoperative maintenance, generator replacement, and revision states. Patients were simulated in 3-month increments for 15 years or until death. Key variables included Charlson Comorbidity Index, CIED type, legacy versus extended battery longevity, mortality rates (procedure and all-cause), infection and non-infectious complication rates, and care settings. Costs included procedure-related (facility and professional), maintenance, and infections and non-infectious complications, all derived from Medicare data (2004-2014, 5\%
\end{abstract}

Electronic supplementary material The online version of this article (https://doi.org/10.1007/s10840-017-0289-8) contains supplementary material, which is available to authorized users.

Jordana K. Schmier

jschmier@exponent.com

1 Exponent, Inc., 1800 Diagonal Road, Suite 500, Alexandria, VA 22314, USA

2 Exponent, Inc., Menlo Park, CA, USA

3 Exponent, Inc., Philadelphia, PA, USA

4 Thomas Jefferson University, Philadelphia, PA, USA sample). Outcomes included counts of battery replacements, revisions, infections and non-infectious complications, and discounted (3\%) costs and life years. An increase in battery longevity in ICDs yielded reductions in numbers of revisions (by 23\%), battery changes (by 44\%), infections (by 23\%), non-infectious complications (by 10\%), and total costs per patient (by 9\%). Analogous reductions for CRT-Ds were $23 \%$ (revisions), 32\% (battery changes), 22\% (infections), $8 \%$ (complications), and $10 \%$ (costs).

Conclusion Based on modeling results, as battery longevity increases, patients experience fewer adverse outcomes and healthcare costs are reduced. Understanding the magnitude of the cost benefit of extended battery life can inform budgeting and planning decisions by healthcare providers and insurers.

Keywords Battery life $\cdot$ Cardiac resynchronization therapy devices $\cdot$ Costs and cost analysis $\cdot$ Device battery replacement . Device longevity

\section{Introduction}

The use of cardiac implantable electronic devices (CIEDs) has been increasing in recent decades in the USA and worldwide $[1,2]$. Both implantable cardiac defibrillators (ICDs) and cardiac resynchronization therapy defibrillators (CRT-Ds) have been associated with decreased mortality in patients with cardiomyopathy and heart failure associated with conduction delays [3]. In addition, patients with a history of life-threatening ventricular arrhythmias have improved survival with CIED implantation compared to antiarrhythmic drug therapy $[4,5]$. The effectiveness of CIED implantation is tempered by the risks associated with the procedure. These risks include infections and non-infectious complications from the initial 
implantation or subsequent revision procedure [6-11]. Infection rates appear to be increasing faster than the rate of implantations [12,13], only some of which can be explained by factors such as gender, comorbidities, or procedure complexity $[1,14]$. It is well-understood that repeat procedures place the patient at higher risk for developing CIED infection $[6,9,15]$. Therefore, strategies to decrease the number of repeat CIED procedures are needed.

Device selection can be driven by many factors, including hospital policies and technology adoption practices $[16,17]$ and patient characteristics [18]. There are also studies directly comparing product performance and claims (e.g., von Gunten et al. [19], Zanon et al. [20]). A focus of several of these studies is on the increased longevity of selected CIEDs and the clinical and economic benefits associated with an extended device lifespan [21-23]. It stands to reason that longer device life would be associated with fewer pulse generator replacements and therefore costs should be lower, both because of fewer surgeries and the lowered risk and costs associated with surgical complications. There is also a tradeoff between battery longevity and maintaining the most contemporary technology in a given patient. In addition, patients who are candidates for ICD or CRT therapy typically have a number of significant medical comorbidities that affect their projected survival. A pulse generator with prolonged battery life would have little clinical value in a patient who is unlikely to survive until the time of elective pulse generator replacement. The case is not always clear-cut; however, clinicians need tools to help them with decision-making. They must balance the relative advantages and disadvantages of various features, including size, shape, lead technologies, and battery longevity as well as patient preferences. Yet, we are unaware of any studies that have explicitly modeled the impact of increased battery longevity on clinical outcomes and costs. Such models may be useful tools to guide physicians in making these clinical decisions with their patients.

The objective of this analysis was to compare changes in patient outcomes and payer costs attributable to increases in ICD and CRT-D battery life. The model characterizes complications and costs associated with CIED-related complications after a primary implantation. The model also includes a number of patient comorbidities, which affect overall survival. Analyses are specific to a patient cohort, a device type and battery length; comparisons reflect differences in costs and event rates experienced by patients for whom that device/battery was implanted.

\section{Methods}

\subsection{Model structure}

A state-transition (Markov) model was developed to estimate downstream health effects and payer-perspective costs following implantation of ICD and CRT-D devices. Model states represent defined phases of care (primary implantation, postoperative maintenance, revision, battery replacement) and an absorbing state (dead). Patients are simulated one at a time (i.e., at the patient level); patients face device procedurerelated risks and mortality risks and accrue costs over a defined time horizon.

Figure 1 illustrates the ways in which patients flow through different paths in the model. The Markov states are indicated with letters; arrows indicate paths and transitions. Each transition has a probability associated with it; sources for probability values are presented in Table 1 . These values were derived from an analysis of the Medicare data, using methods described in the "Input Data" section. Table 1 summarizes the high and low values for each of the scenarios. For example, the analysis identified the median and range of institutional and professional costs for the first quarter for patients who received an implant for inpatient and outpatient setting, for both device types, and for each of the three health categories (levels of the Charlson Comorbidity Index, 0-1, 2-3, and 4+). Each of these combinations was used in separate runs of the model, so that the model could be run only with inpatients with an ICD who had a Charlson Comorbidity score of $0-1$ or patients who received a CRT-D as an outpatient and had a Charlson Comorbidity score greater than 4 , for example. Some of these analyses are presented in detail in this manuscript; others are summarized. All patients enter the model at the primary implantation state (Markov state A). Following the implant, most patients proceed to the postoperative maintenance state (Markov state B); a small percentage requires a revision (Markov state D) in the next cycle. Most patients who enter the postoperative maintenance state remain there for multiple cycles. Battery replacements (Markov state C) can only happen after one or more cycles of postoperative maintenance, reflecting real-world patterns. Following a battery replacement, patients return to the postoperative maintenance state. Patients can remain in the same state for multiple cycles, indicated by loops, such as the loops shown on states B and D. "Dead" (Markov state E) is a terminal/absorbing state, meaning that there is no exit once patients have entered the state.

The model time horizon is fixed at 15 years and each cycle's duration is one calendar quarter. An annual discount rate of $3 \%$ was applied to both total costs and life years to account for the net present value of healthcare costs. The model was designed and implemented using TreeAge Pro 2016 (TreeAge Software, Inc., Williamstown, MA) with an Excel graphic user interface available to control selected model inputs.

Simulating at the patient level allows for heterogeneity among patients and introduces history to the Markov states. Random variation across patients was introduced by simulating individual patients (Monte Carlo simulations) for each set of model parameters. The number of simulated patients per 


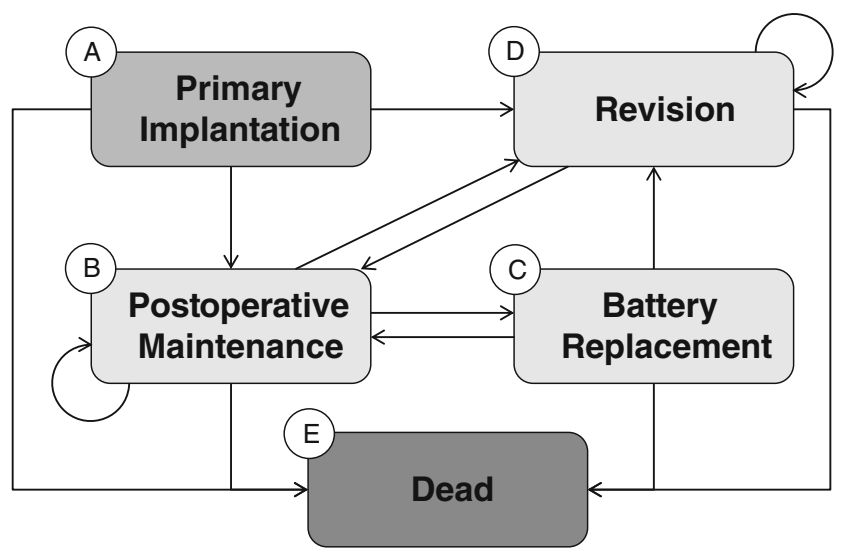

Fig. 1 Markov state diagram

model run was 20,000 , using a fixed seed to reduce individual variation.

\subsection{Input data}

The primary source for model input data was de-identified administrative claims data (known as the Limited Data Set (LDS)) associated with the 5\% sample of Medicare beneficiaries available from the Centers for Medicare and Medicaid Services (CMS). This 5\% sample is equivalent to about 2.5 million Medicare beneficiaries. The LDS data files contain the healthcare service records from inpatient and outpatient encounters generated by these 2.5 million individuals. The data consist of seven components: institutional claims (inpatient, outpatient facility, durable medical equipment, home care, hospice, and skilled nursing facility) and professional claims (Part B). Beneficiaries in the 5\% sample were systematically drawn and represent the broad spectrum of Medicare enrollees across age, gender, race, and geographic region. Each beneficiary was assigned a synthetic identification number, which allows longitudinal tracking of subsequent infection, revision, and other complications following the initial implant. Medicare claims were queried to identify beneficiaries with primary ICD or CRT-D implantations between January 1, 2004, and December 31, 2014. Primary ICD and CRT-D implantation was identified from Current Procedural Terminology (CPT) 33249. The concurrent presence of the CPT code 33225 suggested a CRT-D was implanted.

A full list of diagnosis and procedure codes that were used to identify primary implantation, revisions, battery replacements, and complications is provided in Supplemental Table 1. Model inputs for the reference and sensitivity analyses are provided in Table 1. Costs, transition rates between states (e.g., operative and other cause mortality rates), and event rates (e.g., rates of lead infection or dislodgement) were derived from the $5 \%$ sample. The time period from which data were derived varies. Transition rates and costs were derived using the entire period for which data were available (i.e.,
2004-2014), although costs were inflated to January 2016 dollars. To reflect current trends in setting of care, the distribution of inpatient versus outpatient settings was derived from 2012 to 2014 data.

\subsubsection{Patient and claim identification}

In the retrospective Medicare claims analysis from which data were derived, beneficiaries entered the cohort continuously during the study period, starting on January 1, 2004, and were followed until the end of the study period (December 31, 2014), until they withdrew from Medicare or switched to a Medicare fee-for-service plan or until death. Beneficiaries were required to have been enrolled from January 1, 2003, with no study procedures during that year, to increase the likelihood that the first study procedure from 2004 forward was the patient's initial CIED implant procedure. The beneficiary's status was tracked using the matching 20042014 Medicare enrollment files, which provide annual age, resident state, entitlement status, date of death, and other enrollment information. Beneficiaries younger than 65 years old, those residing outside of the 50 US states, or those enrolled in Medicare-HMO programs whose claims were not submitted to CMS were excluded from this study. For each beneficiary in the cohort, healthcare service claims starting from the initial implant were extracted from the Medicare claims data, including claims for hospital stays, outpatient clinic visits, physician service, skilled nursing care, home health services, and hospice services. The overall health status of the beneficiary at time of the initial installation was characterized by the Charlson Comorbidity Index (CCI), a tool that uses comorbidities to describe wellness and to predict mortality and future healthcare resource use. Diagnoses and surgical procedures performed during this one-year pre-implant period were compiled for the calculation of the CCI.

Beneficiaries with CIED-related infections, either local pocket infection or systemic endovascular infection, were identified by either the ICD-9-CM diagnosis code 996.61 or any diagnosis code for cardiac device infection, fever, bacteremia, endocarditis, cellulitis, or sepsis. These diagnoses were required to be accompanied by a generator removal, system revision, lead revision, or pocket revision procedure on the same claim record in order to be identified as a device procedure-related infection. In addition to infection, other non-infection complications of interest include cardiac perforation, pneumothorax, cardiac arrest, pulmonary embolus, and hematoma. Supplemental Table 1 includes a full list of codes used to identify each procedure and complication. We calculated the quarterly risk of infection and non-infection complications following the primary installation. In addition, we also calculated the risk of infection and non-infection complication following a battery revision and following other types of revisions. Duration of battery life was classified as either 
Table 1 Descriptions of input costs, proportions, and event rates

\begin{tabular}{|c|c|c|c|c|}
\hline Category & Input & Stratified by ${ }^{\mathrm{a}}$ & $\begin{array}{l}\text { Distribution (if appropriate) } \\
\text { values }\end{array}$ & Comment/source \\
\hline \multirow{23}{*}{$\begin{array}{l}\text { Quarterly } \\
\text { costs }\end{array}$} & \multirow[t]{7}{*}{ Primary implant } & Setting & Lognormal & \multirow[t]{7}{*}{ Derived from CMS data } \\
\hline & & Component & Reference range, inpatient: & \\
\hline & & Device type & Institution: $\$ 48,390-\$ 52,243$ & \\
\hline & & Charlson category & Professional: \$1168-\$1517 & \\
\hline & & & Reference range, outpatient: & \\
\hline & & & Institution: $\$ 29,472-\$ 32,077$ & \\
\hline & & & Professional: \$992-\$1333 & \\
\hline & \multirow[t]{7}{*}{ Revision } & Setting & Lognormal & \multirow[t]{7}{*}{ Derived from CMS data } \\
\hline & & Component & Reference range, inpatient: & \\
\hline & & Device type & Institution: $\$ 33,352-\$ 49,522$ & \\
\hline & & Charlson category & Professional: \$649-\$939 & \\
\hline & & & Reference range, outpatient: & \\
\hline & & & Institution: $\$ 14,582-\$ 21,199$ & \\
\hline & & & Professional: $\$ 583-\$ 747$ & \\
\hline & \multirow[t]{3}{*}{ Battery change } & Component & Lognormal & \multirow{3}{*}{$\begin{array}{l}\text { All battery changes were assumed to be } \\
\text { performed on an outpatient basis }\end{array}$} \\
\hline & & Device type & Reference range, outpatient: $\$ 24,054-\$ 25,289$ & \\
\hline & & Charlson category & & \\
\hline & \multirow[t]{2}{*}{ Follow-up cycle } & Device type & Lognormal & \multirow{2}{*}{$\begin{array}{l}\text { Professional and institutional costs were } \\
\text { summed }\end{array}$} \\
\hline & & Charlson category & Reference range: $\$ 80-\$ 164$ & \\
\hline & \multirow[t]{2}{*}{ Complication } & Device type & Beta & \multirow{2}{*}{$\begin{array}{l}\text { Professional and institutional costs were } \\
\text { summed }\end{array}$} \\
\hline & & Charlson category & Reference range: $\$ 896-\$ 1150$ & \\
\hline & \multirow[t]{2}{*}{ Infection } & Device type & Beta & \multirow{2}{*}{$\begin{array}{l}\text { Professional and institutional costs were } \\
\text { summed }\end{array}$} \\
\hline & & Charlson category & Reference range: $\$ 23,817-\$ 40,841$ & \\
\hline \multirow[t]{6}{*}{ Proportions } & \multirow{2}{*}{$\begin{array}{l}\text { Case mix (Charlson } \\
\text { categories) }\end{array}$} & Device type & N/A & \multirow{2}{*}{$\begin{array}{l}\text { Alternative tables provided for shifting } \\
\text { patients to higher (sicker) or lower } \\
\text { (healthier) categories }\end{array}$} \\
\hline & & & $\begin{array}{l}\text { Reference case: } 24-25 \% \text { CCI } 0-2 \text {, } \\
\quad 56-58 \% \text { CCI } 3-4,18-20 \% \text { CCI } 5+\end{array}$ & \\
\hline & \multirow{2}{*}{$\begin{array}{l}\text { Setting (inpatient or } \\
\text { outpatient) of } \\
\text { primary implant }\end{array}$} & Device type & N/A & \multirow[t]{2}{*}{ Alternatives provided to CMS defaults } \\
\hline & & Charlson category & $\begin{array}{l}\text { Reference case: } 56 \% \text { ICD, } 58 \% \text { CRT-D } \\
\text { inpatient }\end{array}$ & \\
\hline & \multirow{2}{*}{$\begin{array}{l}\text { Setting (inpatient or } \\
\text { outpatient) of } \\
\text { revision }\end{array}$} & Device type & N/A & \multirow[t]{2}{*}{ Alternatives provided to CMS defaults } \\
\hline & & Charlson category & $\begin{array}{l}\text { Reference case: } 32-51 \% \text { inpatient (depending } \\
\text { on device and CCI) }\end{array}$ & \\
\hline \multirow[t]{18}{*}{ Event rates } & \multirow[t]{3}{*}{ Battery depletion } & Device type & N/A & \multirow[t]{3}{*}{ Averaged over all patients } \\
\hline & & Battery life & Reference case: Legacy, from CMS; Extended, & \\
\hline & & $\begin{array}{l}\text { Time since last } \\
\text { generator } \\
\text { change }\end{array}$ & Chelu et al. [24] & \\
\hline & Revisions for other & Device type & N/A & Averaged over all patients \\
\hline & reasons & $\begin{array}{l}\text { Time since last } \\
\text { revision }\end{array}$ & $\begin{array}{l}\text { Reference case: } 0-2 \% \text {, depending on } \\
\text { device and CCI }\end{array}$ & \\
\hline & Complications in 1 st & Device type & $\mathrm{N} / \mathrm{A}$ & \\
\hline & $\begin{array}{l}\text { year after primary } \\
\text { implant }\end{array}$ & Charlson category & $\begin{array}{l}\text { Reference case: } 4-7 \% \text {, depending on } \\
\text { device and CCI }\end{array}$ & \\
\hline & Complications in 1 st & Device type & N/A & \\
\hline & year after revision & Charlson category & $\begin{array}{l}\text { Reference case: } 6-8 \% \text {, depending on } \\
\text { device and CCI }\end{array}$ & \\
\hline & Complications in 1 st & Device type & N/A & \\
\hline & $\begin{array}{l}\text { year after generator } \\
\text { change }\end{array}$ & Charlson category & $\begin{array}{l}\text { Reference case: } 2-3 \% \text {, depending on } \\
\text { device and CCI }\end{array}$ & \\
\hline & Infections in 1st year & Device type & $\mathrm{N} / \mathrm{A}$ & \\
\hline & $\begin{array}{l}\text { after primary } \\
\text { implant }\end{array}$ & Charlson category & $\begin{array}{l}\text { Reference case: } 2-4 \% \text {, depending on } \\
\text { device and CCI }\end{array}$ & \\
\hline & Infections in 1st year & Device type & $\mathrm{N} / \mathrm{A}$ & \\
\hline & after revision & Charlson category & $\begin{array}{l}\text { Reference case: } 1-3 \% \text {, depending on } \\
\text { device and CCI }\end{array}$ & \\
\hline & Infections in 1st year & Device type & $\mathrm{N} / \mathrm{A}$ & \\
\hline & $\begin{array}{l}\text { after generator } \\
\text { change }\end{array}$ & Charlson category & $\begin{array}{l}\text { Reference case: } 3-7 \% \text {, depending on } \\
\text { device and CCI }\end{array}$ & \\
\hline & $\begin{array}{l}\text { All-cause mortality } \\
\text { rates }\end{array}$ & $\begin{array}{l}\text { Device type } \\
\text { Charlson category }\end{array}$ & N/A & \\
\hline
\end{tabular}


Table 1 (continued)

\begin{tabular}{|c|c|c|c|c|}
\hline \multirow[t]{3}{*}{ Category } & Input & Stratified by ${ }^{a}$ & $\begin{array}{l}\text { Distribution (if appropriate) } \\
\text { values }\end{array}$ & Comment/source \\
\hline & & & $\begin{array}{l}\text { Reference case: Based on age, derived from } \\
\text { Saxon et al. [25] }\end{array}$ & \\
\hline & $\begin{array}{l}\text { Operative mortality } \\
\text { rates }\end{array}$ & Surgical type & $\begin{array}{l}\text { N/A } \\
\text { Reference: primary implantation } 1.7 \% \text {, } \\
\quad \text { revision } 3.4 \% \text {, battery replacement } 0.2 \%\end{array}$ & \\
\hline
\end{tabular}

CCI Charlson Comorbidity Index, CMS Centers for Medicare and Medicaid Services, CRT-D cardiac resynchronization therapy implantable cardioverter defibrillator, ICD implantable cardioverter defibrillator, $N / A$ not applicable

${ }^{a}$ Stratification categories: devices (ICD or CRT-D); Charlson category (0-2, 3-4, or 5+); setting (inpatient or outpatient); component (institutional or professional); surgical type (primary implant, generator change, or revision)

"legacy," which used data derived from the historical CMS claims data, or "extended," for which data from a US-based registry from a manufacturer of an extended battery longevity CIED was used [24]. Although the model uses data for each quarter directly, the time until $50 \%$ of ICDs required revision was 30 quarters in Medicare data versus 52 quarters in the LATITUDE registry and 22 quarters versus 40 quarters for CRT-Ds in the Medicare and registry data, respectively. This distinction allowed us to analyze the impact of device longevity.

\subsubsection{Cost analysis}

We adopted a third-party payer perspective for this study. Cost is represented by the amount paid by the Medicare trust to hospitals, physicians, and other institutions for the care of these elderly cardiac patients. We calculated the institutional costs (hospitals, clinics, nursing facilities, and hospice) as well as professional costs from physicians and other medical professionals. Quarterly costs, aggregated into two categories (institutional and professional), were calculated for patients with a non-zero cost. All costs were adjusted to the January 2016 level by the Consumer Price Index for medical care services published monthly by the US Bureau of Labor Statistics. Part $\mathrm{D}$ (drug costs) and costs that were the patient's responsibility to pay out of pocket were unavailable and were excluded. We calculated cost of the primary installation, the cost associated with infection and non-infection complications, as well as quarterly "maintenance" cost (CPT: 93289, 93282, 93283, $93284,93295,93296,93287$ ) associated with the monitoring and periodic service of the CIED devices.

To capture the typical skew in costs and avoid assignment of negative costs, we assumed costs (with some exceptions; see Table 1) followed a lognormal distribution. Separate professional and institutional costs (with some exceptions; see Table 1) stratified by device and CCI category were drawn every cycle and accrued to patients experiencing events.

\subsection{Model assumptions}

The complexity of the model required a number of assumptions. These are provided in more detail in Supplemental Table 2.

\subsection{Scenarios and analyses}

Setup of the model begins with specifying scenario variables. The reference analysis requires the following parameter settings:

- Device type: ICD or CRT-D devices (run separately)

- Battery lifetime: lifetimes based on CMS data ("legacy") versus an "extended" lifetime (run separately)

- Charlson Comorbidity Index: distribution of CCI based on CMS datasets

- Mortality rates from procedures: Default values based on CMS datasets

- Procedure settings: The inpatient/outpatient ratio for primary implantation and revision based on CMS datasets

- Cost data: based on CMS datasets, inflated to January 2016

Sensitivity analyses examined include a sicker (average higher CCI) population and an average of $20 \%$ more outpatient procedures as well as discounting costs and outcomes at rates of $6 \%$ and $0 \%$ annually to address the lack of consensus on appropriate discounting rates for health economic studies $[26,27]$.

\subsection{Model outputs}

Patient-level event counts, costs, and life years are generated for each model run, specific to a device and battery length. Key outputs of interest include decreases in complications and costs with increasing battery life and numbers of patients 
requiring generator changes or revisions over the 15 -year time horizon (or remaining lifespan).

\section{Results}

Among the ICD and CRT-D recipients identified in the CMS database, mean age was 74.6 (standard deviation 6.1 years) and $73.3 \%$ were male. Across all beneficiaries, approximately one quarter had a CCI score of 2 or less and more than half had a CCI of less than 5 . There were no significant differences in age, sex, or CCI score between ICD and CRT-D patients.

Patients receiving ICDs with a longer battery life were more likely to have no generator changes ( 82.2 versus $68.1 \%$ ), no infections (94.3 versus $92.6 \%$ ), no non-infection complications (91.2 versus $90.2 \%$ ), and no revisions (94.1 versus $92.3 \%$, Table 2) during the modeled period. The relative reduction in each outcome is shown in Fig. 2. Patients receiving CRT-Ds with a longer battery life experienced similar additional benefits (Table 2). As expected, patients with additional procedures incurred greater costs, as shown for the ICD legacy scenario (Fig. 3); the same pattern was shown for other devices and longevity options. A longer battery life was associated with a decrease in total costs for patients with both ICDs and CRT-Ds (Table 2) and practically equivalent life years. Small increases in life years were observed with longer battery life, but as they were consistently less than 1 month of the 15-year model horizon and therefore less than one model cycle, they are treated as equivalent. Patients receiving ICDs with an extended battery had total costs reduced by approximately $\$ 5288$ (9\%) compared to the legacy battery, while patients receiving CRT-Ds with an extended battery had total costs reduced by roughly $\$ 5981$ (10\%). Cost-effectiveness ratios are not defined for extended battery strategies because they are cost saving, that is, extended batteries are associated with better (lower) costs and better (nominally increased) life years outcomes.

Sensitivity analyses both confirmed the model's behavior and provided additional insight. The following examples reflect patients with ICDs, although similar patterns were evident among CRT-D patients. For example, patients who were sicker, operationalized as shifting the Charlson Comorbidity Index, showed the same pattern, with costs for the existing battery life greater than an extended battery life, but with lower costs for each scenario to reflect earlier death. The total discounted life years accrued were almost a full year less than in the base case scenario. Patients who were healthier and had lower CCI scores tended to live longer, but repeat procedure rates were similar to the reference CCI distribution. This is likely because living longer creates more opportunities for the need for battery revisions. Sensitivity analyses also explored the impact of having $20 \%$ more implant and revision procedures performed in outpatient settings. (All battery changes were assumed to be performed in outpatient settings.) There was no difference in life years accumulated, as the model did not assign different mortality rates based on procedure setting, but costs for the legacy and extended battery scenarios were approximately $\$ 2600$ less than the base case setting distribution. Figure 4 shows costs when using the observed proportion of outpatient implant and revision procedures for the legacy and extended battery scenarios for CRTD devices using CMS data on care setting compared to increased use of outpatient care (increasing, for example, the percent of initial ICD implants performed in outpatient settings from 56 to $76 \%$ ). This more accurately reflects recent trends in care settings. Increasing the ratio of outpatient to inpatient procedures lowered costs by $4-5 \%$ over the modeled observation period.

Other sensitivity analyses show the effect of changing input variables. Figure 5 demonstrates how changing the discount rate affects total costs with extended longevity ICD devices. As shown, there is a small but expected decrease with a higher discount rate and an increase with no discount rate. It is not surprising that the discount rate only changes costs slightly; most of the cost for each patient is typically in the first cycle, with the initial implant.

\section{Discussion}

This analysis found that increases in battery life substantially reduce costs and certain unwanted events (infections, generator changes, revisions) and produce equivalent or minimal gains in life expectancy. Extended battery life was the dominant strategy for all examined scenarios. While this finding is consistent with expectations, we believe that presenting empiric evidence of the value of increased battery life can serve multiple purposes. First, the typical evidence stream from randomized controlled trials does not exist for battery components, yet some alternative evidence is often required to demonstrate value. Second, understanding the shift in costs that would be associated with extended battery life can be used for budgeting and planning. Finally, while understanding cost savings associated with longer battery life is valuable for estimating budget impact of CIED use for insurers, estimating repeat hospitalizations can also have value to facilities and healthcare systems in planning inpatient care. For these reasons, understanding the magnitude of the cost benefit of extended battery life warrants analysis rather than assumptions. The UK's National Institute for Health and Care Excellence (NICE) has already considered this question; it developed and issued guidance on its support for a CRT-D with extended battery life based on published evidence [28]. The USA currently employs a fee-for-service approach to healthcare, which predominantly rewards for volume of care. As the USA explores alternative payment models with greater emphasis on 
Table 2 Clinical and cost results, percentages of patients with no adverse events or repeat procedures, costs, and life years

\begin{tabular}{|c|c|c|c|c|c|c|c|}
\hline $\begin{array}{l}\text { Device } \\
\text { and } \\
\text { battery } \\
\text { length }\end{array}$ & $\begin{array}{l}\text { With no } \\
\text { infections } \\
(\%)\end{array}$ & $\begin{array}{l}\text { With no non- } \\
\text { infection } \\
\text { complications } \\
(\%)\end{array}$ & $\begin{array}{l}\text { With no } \\
\text { battery } \\
\text { changes } \\
(\%)\end{array}$ & $\begin{array}{l}\text { With no } \\
\text { revisions } \\
(\%)\end{array}$ & $\begin{array}{l}\text { Neither } \\
\text { battery } \\
\text { change nor } \\
\text { revision }(\%)\end{array}$ & $\begin{array}{l}\text { Total } \\
\text { costs } \\
\text { (mean, } \\
\text { SD) }\end{array}$ & $\begin{array}{l}\text { Life years } \\
\text { (mean, } \\
\text { SD) }\end{array}$ \\
\hline $\begin{array}{l}\text { ICD, } \\
\text { lega- } \\
\text { cy }\end{array}$ & 92.6 & 90.2 & 68.1 & 92.3 & 65.0 & $\begin{array}{c}\$ 56,384 \\
(\$ 32,- \\
385)\end{array}$ & $6.53(4.64)$ \\
\hline $\begin{array}{l}\text { ICD, } \\
\text { ex- } \\
\text { tende- } \\
\text { d }\end{array}$ & 94.3 & 91.2 & 82.2 & 94.1 & 78.5 & $\begin{array}{c}\$ 51,096 \\
(\$ 28,- \\
565)\end{array}$ & $6.54(4.65)$ \\
\hline $\begin{array}{l}\text { CRT-D, } \\
\text { lega- } \\
\text { cy }\end{array}$ & 89.7 & 91.5 & 61.9 & 89.4 & 58.6 & $\begin{array}{c}\$ 62,930 \\
(\$ 36,- \\
599)\end{array}$ & $5.50(4.29)$ \\
\hline $\begin{array}{l}\text { CRT-D, } \\
\text { ex- } \\
\text { tende- } \\
\text { d }\end{array}$ & 92.0 & 92.3 & 74.2 & 91.8 & 70.1 & $\begin{array}{c}\$ 56,949 \\
(\$ 32,- \\
091)\end{array}$ & $5.51(4.28)$ \\
\hline
\end{tabular}

Costs and life years discounted at $3 \%$ annually

CRT-D cardiac resynchronization therapy implantable cardioverter defibrillator, $I C D$ implantable cardioverter defibrillator, $S D$ standard deviation quality outcomes and value of care, it will be particularly important to provide evidence on the economic value of medical therapies and their differentiating properties.

Pulse generator replacements due to battery depletion have typically occurred between 4 and 6 years after ICD implantation [29]. The problem of battery longevity is not new; over the years, multiple factors have contributed to the longstanding observation that battery life is insufficient for the post-implantation survival [30] including trends toward miniaturization, earlier use, and broadening of indications [31]. Further complicating these factors is the pace of innovation. ICD patients may be upgraded to different or more advanced devices before batteries fail or without the presence of a complication. Patients who received ICD upgrades rather than revisions or generator replacements were not excluded from the present analysis. Later review determined that they comprised less than $4 \%$ of ICD "revision" procedures and no adjustments were made. Dual-chamber devices may be

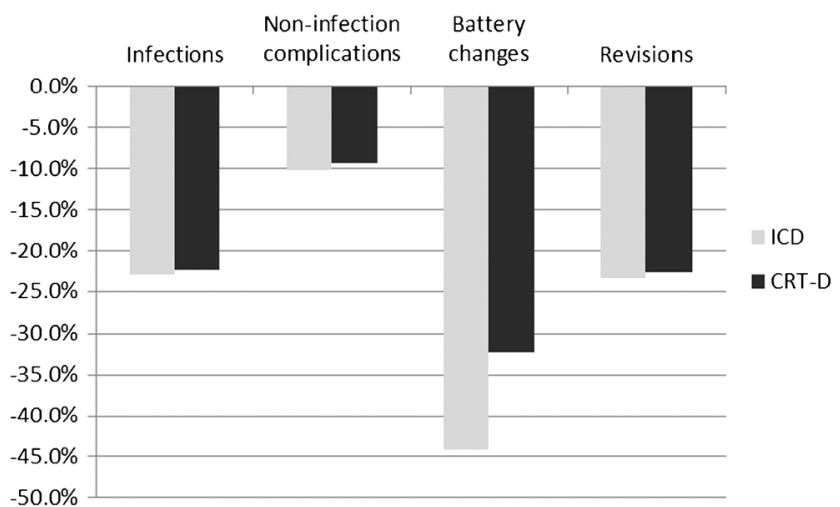

Fig. 2 Change in repeat events, legacy versus extended longevity by device associated with higher short-term complication rates [32], and it is possible that patients who received upgrades may be clinically different than others, but there were insufficient patients to test in this population.

Repeated revision procedures have also been identified as a risk factor for CIED complications, in particular, infection [6, 9, 33]. Unfortunately, the rate of CIED infection appears to be increasing out of proportion to overall device utilization [12-14]. Infection rates may be influenced by multiple factors, including patient comorbidities, but also by many other factors that are not detectable with a claims database [34]. Further refinement of the model could permit incorporating some of the factors, although there are practical limits to what factors can be considered based on the data set and counts of patients in relevant categories. While reducing the need for revisions would not eliminate all infections, as a primary driver of infection, any reduction in revisions would be noteworthy.

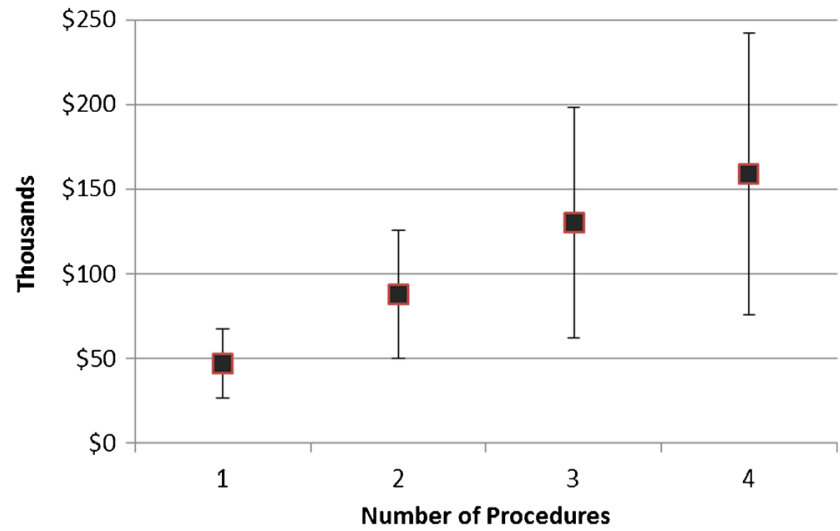

Fig. 3 Mean discounted costs by number of repeat procedures, ICD legacy longevity scenario 


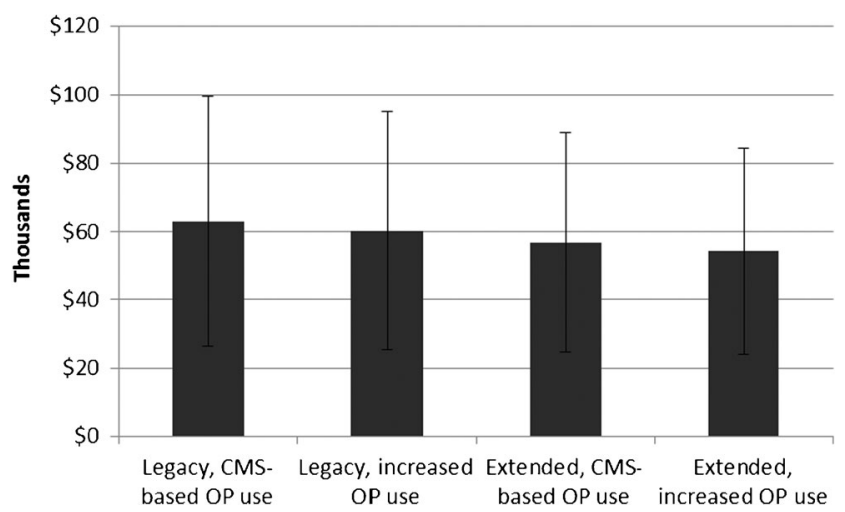

Fig. 4 Sensitivity analysis: change in total costs by longevity and shift to outpatient procedures, CRT-D only

From a clinical perspective, longer battery life with consistent performance seems like an obvious step forward. Payers must weigh clinical benefits against budget implications and are increasingly cognizant of cost-effectiveness of treatment and longterm patient outcomes. Hospitals have even more of a stake in patient success including reducing readmissions than in previous years, as competition for demonstrating quality through improved patient outcomes converges with penalties for unnecessary readmissions. Studies like the model presented here can provide value to multiple audiences. They can help third-party payers consider coverage, assist hospitals in predicting caseload (revisions versus implantations), and potentially help patients who may have a co-pay evaluate how they may benefit from any increased cost to which they may be subject based on battery and device type. Still, it is not logical to cover a device that will long outlast a patient's lifetime; models like this one can help explore in what scenarios increased battery longevity has the greatest impact on different populations.

\subsection{Limitations}

This model was designed to allow the user to account for changes in the setting of implant and revision procedures, which can have a substantial impact on costs, and across levels of patient health, as measured by the Charlson Comorbidity Index. The Charlson Comorbidity Index used for stratifying patients did not explicitly account for patient age, but alternative comorbidity indices could be explored, which would permit correlation of patient age to event rates and mortality risks, as well as costs. In particular, while the age of patients is constrained by the use of the Medicare claims data, there are other clinical factors for which we cannot account using an administrative claims database. Specifically, we do not know about the frequency of pacing or ICD shocks, which could offer substantial insight into battery performance. The administrative nature of the database means that our ability to identify comorbidities and other health-related characteristics is limited to those for which a claim and diagnosis code are present.

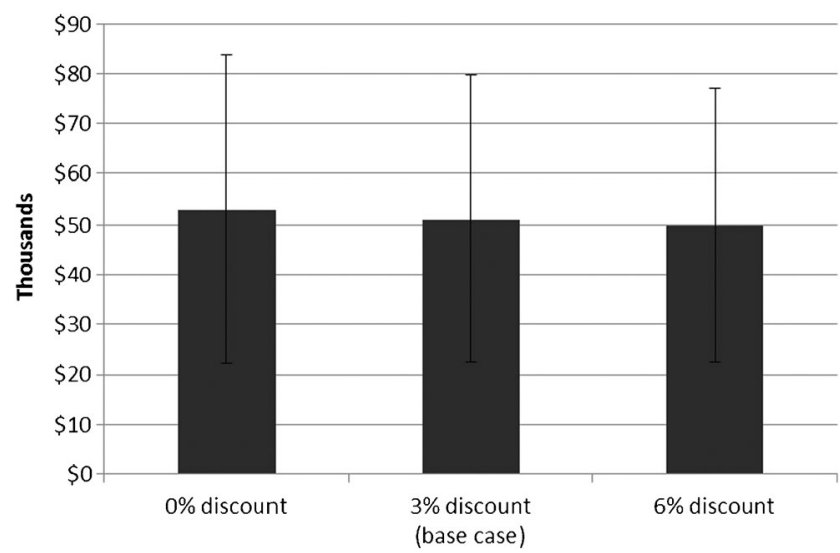

Fig. 5 Sensitivity analysis: effect of discounting on total costs, ICD extended longevity scenario

Although claims have been adjudicated by the time the dataset is available for analysis, the coding may not always be complete. For example, it is possible that there are codes that are not listed because there is no additional reimbursement for them. This analysis, consistent with most claims analyses, assumes that all relevant codes have been submitted as part of each claim. Other factors that were not included in this model may affect outcomes. For example, patient demographic and clinical characteristics, activity levels, battery consumption, and device characteristics may affect outcomes but are not available in a claims database. The model can be modified to include additional parameters as more information becomes available. Similarly, although the model only attributes infections that occur in the first year following a generator change, the model's framework could be used to consider infections that occur over shorter or longer follow-up periods. The one-year window has been used in other CIED claims analyses [35]; longer time periods create greater uncertainty about attribution.

Another important limitation to consider is that this model used data from Medicare beneficiaries age 65 and older. In fact, the Medicare population from whom model input parameters were drawn averaged 74 years old. Selecting only the youngest Medicare beneficiaries with CIEDs would not have provided sufficient counts. Older patients may have fewer years in which to benefit from the CIED, so limiting the input parameters to data from older patients might constrain variation in life expectancy and thus minimize benefits. Recent analyses suggest that the average age at implant of an ICD in the USA is $67 \pm 13$ years, with one fourth of new implants in patients 59 years or younger [36]. Data from younger patients, who could also have fewer comorbidities, could reasonably demonstrate a greater benefit from the use of devices with longer battery lives. Alternatively, these patients receiving CIEDs earlier might be less healthy than those who do not require a device until they are older. Younger patients might be more likely to be in the workforce and have reduced work productivity associated with negative outcomes related to battery life. 
Another concern about the use of the Medicare population for the input parameters and "legacy" battery longevity is that the population in the registry that supplied the "extended" longevity data may differ. It is likely that the Medicare population is more heterogeneous, but the possibility of younger patients in the registry may also affect heterogeneity. It is unclear how much overlap there may be between the Medicare population and the sponsor-initiated registry, as well as whether there are other differences between patients who participate in registries and those who do not.

The model is conservative in estimating the impact of implantations and revisions. It does not include either quality of life or societal costs or incorporate patient preferences, which suggest that patients value longevity over size [37]. Caregiving associated with implantable cardiac devices has been shown to have an impact on the well-being of patients' partners that could translate to an increased health care burden among caregivers [38, 39]. Further, loss of work or other types of indirect costs associated with battery replacements and related adverse events can only increase total economic burden.

\section{Conclusion}

Based on modeling results, as battery longevity increases, patients experience fewer adverse outcomes and healthcare costs are reduced.

Acknowledgements We would like to thank Pamela McMahon, Ph.D., for her work in developing and implementing the initial model.

\begin{abstract}
Author contributions All authors participated in developing the study concept and design. EL conducted much of the data analysis, with JS incorporating the data into the decision tree that had been designed by JK. JS, JP, and EL drafted the manuscript, with JK and AG providing critical revision. All authors provided final review and approval. Funding for the work was secured by JP and JS.FundingBoston Scientific Corporation funded this study. Boston Scientific did not participate in the design and conduct of the study, in the collection, analysis, and interpretation of the data, with the exception of making available registry data on battery longevity that have only been partially published, and in the preparation, review, or approval of the manuscript, with the exception of non-binding comments for style and a legal review.
\end{abstract}

Open Access This article is distributed under the terms of the Creative Commons Attribution 4.0 International License (http:// creativecommons.org/licenses/by/4.0/), which permits unrestricted use, distribution, and reproduction in any medium, provided you give appropriate credit to the original author(s) and the source, provide a link to the Creative Commons license, and indicate if changes were made.

\section{References}

1. Greenspon AJ, Patel JD, Lau E, Ochoa JA, Frisch DR, Ho RT, et al. Trends in permanent pacemaker implantation in the United States from 1993 to 2009: increasing complexity of patients and procedures. J Am Coll Cardiol. 2012;60:1540-5.
2. Kurtz SM, Ochoa JA, Lau E, Shkolnikov Y, Pavri BB, Frisch D, et al. Implantation trends and patient profiles for pacemakers and implantable cardioverter defibrillators in the United States: 19932006. Pacing Clin Electrophysiol. 2010;33:705-11.

3. Bristow MR, Saxon LA, Boehmer J, Krueger S, Kass DA, De Marco T, et al. Cardiac-resynchronization therapy with or without an implantable defibrillator in advanced chronic heart failure. $\mathrm{N}$ Engl J Med. 2004;350:2140-50.

4. Bardy GH, Lee KL, Mark DB, Poole JE, Packer DL, Boineau R, et al. Amiodarone or an implantable cardioverter-defibrillator for congestive heart failure. N Engl J Med. 2005;352:225-37.

5. The Antiarrhythmics versus Implantable Defibrillators (AVID) Investigators. A comparison of antiarrhythmic-drug therapy with implantable defibrillators in patients resuscitated from near-fatal ventricular arrhythmias. N Engl J Med. 1997;337:1576-83.

6. Borleffs CJ, Thijssen J, de Bie MK, van Rees JB, van Welsenes GH, van Erven L, et al. Recurrent implantable cardioverter-defibrillator replacement is associated with an increasing risk of pocket-related complications. Pacing Clin Electrophysiol. 2010;33:1013-9.

7. Prutkin JM, Reynolds MR, Bao H, Curtis JP, Al-Khatib SM, Aggarwal S, et al. Rates of and factors associated with infection in 200909 Medicare implantable cardioverter-defibrillator implants: results from the National Cardiovascular Data Registry. Circulation. 2014;130:1037-43.

8. Polyzos KA, Konstantelias AA, Falagas ME. Risk factors for cardiac implantable electronic device infection: a systematic review and meta-analysis. Europace. 2015;17:767-77.

9. Poole JE, Gleva MJ, Mela T, Chung MK, Uslan DZ, Borge R, et al. Complication rates associated with pacemaker or implantable cardioverter-defibrillator generator replacements and upgrade procedures: results from the REPLACE registry. Circulation. 2010;122:1553-61.

10. Krahn AD, Lee DS, Birnie D, Healey JS, Crystal E, Dorian P, et al. Predictors of short-term complications after implantable cardioverter-defibrillator replacement: results from the Ontario ICD Database. Circ Arrhythm Electrophysiol. 2011;4:136-42.

11. Ferguson TB Jr, Ferguson CL, Crites K, Crimmins-Reda P. The additional hospital costs generated in the management of complications of pacemaker and defibrillator implantations. J Thorac Cardiovasc Surg. 1996;111:742-51. discussion 51-2

12. Cabell CH, Heidenreich PA, Chu VH, Moore CM, Stryjewski ME, Corey GR, et al. Increasing rates of cardiac device infections among Medicare beneficiaries: 1990-1999. Am Heart J. 2004;147:582-6.

13. Greenspon AJ, Patel JD, Lau E, Ochoa JA, Frisch DR, Ho RT, et al. 16-year trends in the infection burden for pacemakers and implantable cardioverter-defibrillators in the United States 1993 to 2008. J Am Coll Cardiol. 2011;58:1001-6.

14. Voigt A, Shalaby A, Saba S. Continued rise in rates of cardiovascular implantable electronic device infections in the United States: temporal trends and causative insights. Pacing Clin Electrophysiol. 2010;33:414-9.

15. Palmisano P, Accogli M, Zaccaria M, Luzzi G, Nacci F, Anaclerio $\mathrm{M}$, et al. Rate, causes, and impact on patient outcome of implantable device complications requiring surgical revision: large population survey from two centres in Italy. Europace. 2013;15:531-40.

16. Lampert R, Wang Y, Curtis JP. Variation among hospitals in selection of higher-cost, "higher-tech," implantable cardioverter-defibrillators: data from the National Cardiovascular Data Registry (NCDR) implantable cardioverter/defibrillator (ICD) registry. Am Heart J. 2013;165:1015-23.e2.

17. Shah B, Hernandez AF, Liang L, Al-Khatib SM, Yancy CW, Fonarow GC, et al. Hospital variation and characteristics of implantable cardioverter-defibrillator use in patients with heart failure: data from the GWTG-HF (Get With The Guidelines-Heart Failure) registry. J Am Coll Cardiol. 2009;53:416-22. 
18. Lindvall C, Chatterjee NA, Chang Y, Chernack B, Jackson VA, Singh JP, et al. National trends in the use of cardiac resynchronization therapy with or without implantable cardioverter-defibrillator. Circulation. 2016;133:273-81.

19. von Gunten S, Schaer BA, Yap SC, Szili-Torok T, Kuhne M, Sticherling C, et al. Longevity of implantable cardioverter defibrillators: a comparison among manufacturers and over time. Europace. 2016;18:710-7.

20. Zanon F, Martignani C, Ammendola E, Menardi E, Narducci ML, De Filippo P, et al. Device longevity in a contemporary cohort of ICD/CRT-D patients undergoing device replacement. J Cardiovasc Electrophysiol. 2016;27:840-5.

21. Horlbeck FW, Mellert F, Kreuz J, Nickenig G, Schwab JO. Realworld data on the lifespan of implantable cardioverter-defibrillators depending on manufacturers and the amount of ventricular pacing. $\mathrm{J}$ Cardiovasc Electrophysiol. 2012;23:1336-42.

22. Ramachandra I. Impact of ICD battery longevity on need for device replacements-insights from a Veterans Affairs database. Pacing Clin Electrophysiol. 2010;33:314-9.

23. Knops P, Theuns DA, Res JC, Jordaens L. Analysis of implantable defibrillator longevity under clinical circumstances: implications for device selection. Pacing Clin Electrophysiol. 2009;32:1276-85.

24. Chelu M, Hammill E, Wold N, Saba S. The effect of device programming and delivered therapy on high voltage device longevity - the ALTITUDE(tm) Longevity Study. Heart Rhythm Soc. 2016;13:S102.

25. Saxon LA, Hayes DL, Gilliam FR, Heidenreich PA, Day J, Seth M, et al. Long-term outcome after ICD and CRT implantation and influence of remote device follow-up: the ALTITUDE survival study. Circulation. 2010;122:2359-67.

26. Paulden M, O'Mahony JF, McCabe C. Discounting the recommendations of the second panel on cost-effectiveness in health and medicine. PharmacoEconomics. 2017;35:5-13.

27. Sanders GD, Neumann PJ, Basu A, Brock DW, Feeny D, Krahn M, et al. Recommendations for conduct, methodological practices, and reporting of cost-effectiveness analyses: second panel on costeffectiveness in health and medicine. JAMA. 2016;316:1093-103.

28. National Institute for Health and Care Excellence. ENDURALIFE powered CRT-D devices for treating heart failure. 2017. Available at https://www.nice.org.uk/guidance/mtg33.

29. Kramer DB, Kennedy KF, Noseworthy PA, Buxton AE, Josephson ME, Normand SL, et al. Characteristics and outcomes of patients receiving new and replacement implantable cardioverter- defibrillators: results from the NCDR. Circ Cardiovasc Qual Outcomes. 2013;6:488-97.

30. Hauser RG. The growing mismatch between patient longevity and the service life of implantable cardioverter-defibrillators. J Am Coll Cardiol. 2005;45:2022-5.

31. Neuzner J. The mismatch between patient life expectancy and the service life of implantable devices in current cardioverterdefibrillator therapy: a call for larger device batteries. Clin Res Cardiol. 2015;104:456-60.

32. Peterson PN, Varosy PD, Heidenreich PA, Wang Y, Dewland TA, Curtis JP, et al. Association of single- vs dual-chamber ICDs with mortality, readmissions, and complications among patients receiving an ICD for primary prevention. JAMA. 2013;309:2025-34.

33. Gould PA, Krahn AD, Canadian Heart Rhythm Society Working Group on Device A. Complications associated with implantable cardioverter-defibrillator replacement in response to device advisories. JAMA. 2006;295:1907-11.

34. Baddour LM, Epstein AE, Erickson CC, Knight BP, Levison ME, Lockhart PB, et al. Update on cardiovascular implantable electronic device infections and their management: a scientific statement from the American Heart Association. Circulation. 2010;121:458-77.

35. Sohail MR, Eby EL, Ryan MP, Gunnarsson C, Wright LA, Greenspon AJ. Incidence, treatment intensity, and incremental annual expenditures for patients experiencing a cardiac implantable electronic device infection: evidence from a large US payer database 1-year post implantation. Circ Arrhythm Electrophysiol 2016;9:e03929.

36. Kremers MS, Hammill SC, Berul CI, Koutras C, Curtis JS, Wang Y, et al. The national ICD registry report: version 2.1 including leads and pediatrics for years 2010 and 2011. Heart Rhythm. 2013;10: e59-65.

37. Wild DM, Fisher JD, Kim SG, Ferrick KJ, Gross JN, Palma EC. Pacemakers and implantable cardioverter defibrillators: device longevity is more important than smaller size: the patient's viewpoint. Pacing Clin Electrophysiol. 2004;27:1526-9.

38. Brouwers C, Caliskan K, de Jonge N, Theuns DA, Constantinescu A, Young QR, et al. A comparison of the health status and psychological distress of partners of patients with a left ventricular assist device versus an implantable cardioverter defibrillator: a preliminary study. Heart Lung. 2015;44:27-32.

39. Nicholas Dionne-Odom J, Hooker SA, Bekelman D, Ejem D, McGhan G, Kitko L, et al. Family caregiving for persons with heart failure at the intersection of heart failure and palliative care: a stateof-the-science review. Heart Fail Rev. 2017;22:543-57. 